
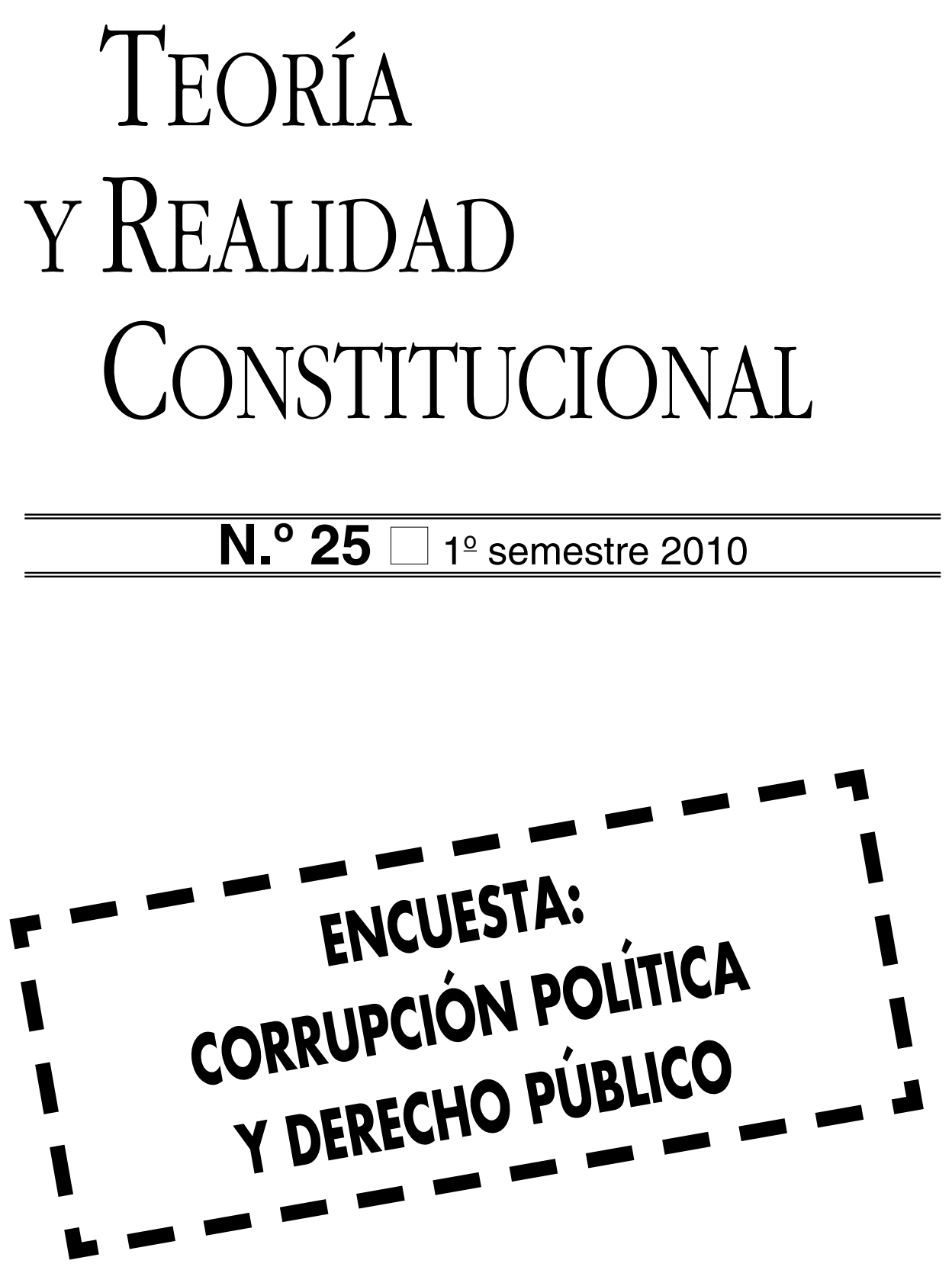


\title{
LA REGULACIÓN DE LOS CONSEJOS AUDIOVISUALES EN EL ORDENAMIENTO JURÍDICO ESPAÑOL
}

\author{
MARÍA LUISA BALAGUER CALLEJÓN \\ Catedrática de Derecho Constitucional \\ Universidad de Málaga
}

SUMARIO

I. Introducción.

II. La regulación constitucional de los medios de comunicación.

III. La regulación de los medios de comunicación en el ordenamiento jurídico del Estado.

IV. Mecanismos de control de los contenidos.

V. Conclusiones.

\section{INTRODUCCIÓN}

Los medios de comunicación constituyen, desde el punto de vista del derecho constitucional, la expresión de la garantía de una configuración democrática de la sociedad y de la política. ${ }^{1}$ El art. $20 \mathrm{CE}$ regula el reconocimiento y protección de un grupo de derechos derivados de la libertad de expresión, con las garantías de su ejercicio. Esta profusa regulación en el art. 20 de tan amplios y variados derechos, tiene una razón histórica clara, en el régimen al que pone fin la Constitución, en el que no hubo libertad de expresión ni de información, sino censura previa y adoctrinamiento ideológico del Estado.

1 El Tribunal Constitucional en sus primeras sentencias ha relacionado directamente el principio de legitimidad democrática regulado en el art. 1.2 CE con el art. 20 CE. (STC 6/1981, Fj. n. 3 que considera que la preservación de la comunicación pública libre es la condición sin la cual "no hay sociedad libre ni, por tanto, soberanía popular"). 
Esta circunstancia histórica ha condicionado de manera importante, no solamente la regulación constitucional, sino la creación de una dogmática jurídica apropiada a una nueva realidad, en la que los derechos derivados de la libertad de expresión, se configuran sobre todo en contraposición con la situación histórica anterior. La necesidad de la creación de una opinión pública libre, en relación con la falta de libertad informativa de la dictadura, constituye una exigencia de la democracia misma ${ }^{2}$. La relación entre los derechos de libertad de expresión y los valores constitucionales, es una relación de medio a fin. Solo con la garantía del ejercicio de esos derechos es posible un Estado democrático de derecho, en el que se dé cumplimiento a los valores superiores del ordenamiento, la igualdad, la libertad, la justicia y el pluralismo político recogidos en el art. 1.1 CE. La prevalencia de los derechos reconocidos en el art. 20 respecto de otros derechos fundamentales, deviene de esa implicación con los valores del Estado Social. De ahí la posición preferente de la libertad de expresión como derecho colectivo, respecto del derecho al honor o la intimidad, como derechos individuales. ${ }^{3}$

\section{LA REGULACIÓN CONSTITUCIONAL DE LOS MEDIOS DE COMUNICACIÓN}

En cuánto a los medios de comunicación, como instrumentos de realización de estos valores constitucionales, el pf. 3 del art. 20 también condiciona su creación y funcionamiento. Hay una exigencia de control parlamentario que debe concretarse legalmente.

De ahí que la inicial configuración de los medios de comunicación parecía haber optado claramente por un modelo de creación y gestión pública.

2 Opinión pública entendida como "conjunto de normas que regulan la comunicación pública como un cauce de participación en el Estado democrático, consistente en la garantía jurídica de la formación de la opinión individual y colectiva, presupuesto de la voluntad jurídica del Estado". I. VILLAVERDE MENÉNDEZ, "Estado democrático e información: el derecho a ser informado". Edit. Junta General del Principado de Asturias". Oviedo. 1994, pág. 193. Similar concepción en F. BASTIDA FREIJEDO, "El régimen jurídico de la comunicación social", Instituto de Estudios Económicos. Madrid. 1994. El autor considera la formación de la opinión pública como un proceso, distinguiendo entre la formación de una opinión pública libre, y la formación libre de la opinión pública, págs. 12-14.

3 Sobre la inversión valorativa de los derechos de información sobre el honor, en relación con la interpretación judicial de estos derechos, M. L. BALAGUER, "El derecho fundamental al honor». Edit. Tecnos. Madrid. 1992. Pág. 161. En lugar de la presunción del "animus iniuriandi", que los jueces anteriores a la Constitución, consideraban en contraposición con la información de una noticia, el Tribunal Constitucional, en aplicación de la doctrina del TEDH impondrá la posición preferente del derecho de libertad de expresión, y la presunción del "animus informandi». (Desde la STC 30/1982). Esta técnica resulta decisiva para el enjuiciamiento del "balancing" de los derechos derivados del art. $18 \mathrm{CE}$ en relación con el 20, porque esa intención informativa está justificada por la realización de los valores constitucionales, y despliega una importante eficacia en la protección de los derechos colectivos sobre los individuales. Solamente cuándo no se justifica la necesidad informativa, se analiza la lesión de los derechos al honor o a la intimidad. 
Parecía inicialmente una opción legislativa mas garante del cumplimiento de esos fines constitucionales. Pero pronto no sería posible mantener esa opción, no solamente porque las propias razones de la garantía del pluralismo se imponían, sino sobre todo porque el desarrollo tecnológico de los medios de comunicación no permitía el mantenimiento del monopolio informativo. Consecuencia de ello será la progresiva apertura en las Leyes 10/1988 de la televisión privada, 37/1995, de televisión por satélite, y 41/1995 de televisión por cable.

A esa consideración restrictiva de este concepto, se abrirá también la consideración jurisprudencial de que esa opinión pública no puede ser detentada en exclusiva por los poderes públicos, y permitirá la entrada a la televisión privada. ${ }^{4}$ Por otra parte, la Ley 46/1983, ya había reconocido a las CC.AA. las posibilidades de intervenir en la Administración de los entes de radiotelevisión, de modo que cuándo se regula la televisión privada, en la Ley 10/1988, las CC.AA. tendrán asumidas algunas competencias en la materia. ${ }^{5}$

\section{LA REGULACIÓN DE LOS MEDIOS DE COMUNICACIÓN EN EL ORDENAMIENTO JURÍDICO DEL ESTADO.}

Al momento de redactarse la Constitución Española de 1978, los medios de comunicación en España eran sin excepción, de titularidad estatal, y su funcionamiento estuvo durante los largos años de la dictadura, al régimen de censura previa. La apertura del sistema lo fue siendo también paralelamente de los medios, pero la Ley 14/1966, de Prensa mantenía en total incertidumbre los contenidos emitidos por la ambigüedad de la redacción del art. 2 que al regular la extensión de lo que pudiera llamarse libertad de expresión, ponía como límite el orden público. El RDL 24/1977, de 1 de abril, de libertad de expresión derogó el contenido del art. 2, pero la situación, sin ánimo de entrar a considerar con más detalle las circunstancias de la época, sobre las que existe una interesante y amplia literatura, era inestable jurídicamente por las facultades gubernativas en materia de secuestro y suspensión de la prensa. El debate parlamentario de la aprobación de la Constitución Española estuvo mediatizado por esa situación, y el resultado fue una consideración de los medios de comunicación libres de todo condicionamiento, que niegan la posibilidad de censura previa o secuestro de publicaciones, salvo con las garantías judiciales.

4 SSTC 31, 47, 98, 240 y 307/1994.

5 Posteriormente, la Ley 41/1995, de televisión local por ondas, otorga a las CC.AA. competencias en materia de concesiones administrativas y sancionadoras, y la Ley $42 / 1995$, de telecomunicaciones por cable. La Disposición adicional 44 de la Ley 66/1997, de medidas fiscales, administrativas y del orden social, en lo que se refiere al ámbito local. 


\section{a) LA RADIOTELEVISIÓN COMO SERVICIO PÚBLICO ESTATAL}

La consideración de la RTVE como un servicio público no fue en ningún momento discutida ni por la doctrina ni por la jurisprudencia. La necesidad de garantizar desde los poderes públicos, la asepsia y la neutralidad informativas, bien cierto es que solamente desde un marco puramente teórico, exigían una televisión pública que garantizase las exigencias constitucionales, no solamente del art. $20 \mathrm{CE}$, sino también de otros preceptos como el art. 1.1 cuya satisfacción requería la garantía de los poderes públicos. Así, la STC 12/1982, deniega el amparo a Antena 3 en su solicitud del derecho a establecer, gestionar, y explotar la producción y transmisión de imágenes y sonidos por medio de la televisión. Se considera como decisión del legislador el establecimiento de una gestión privada del servicio público de la TV. (Fj. 5) y exige que esa regulación se haga por una ley orgánica.

A esa inicial concepción de servicio publico que se contiene en la STC 12/1982, le sigue una puntualización importante en la STC 74/1982, que matiza como el hecho de ser la Televisión un servicio público no impide la gestión mediante concesión administrativa. (Fj. 3). Criterio que será ratificado en las SSTC 35/1983, 106/1986, 206/1990, 119/1991, y 31/1994. No deja de ser cierto también que una vía de apertura ya se contiene en la STC 74/82, en donde se considera que la TV privada no está impuesta por la Constitución pero tampoco prohibida. Y que corresponde su decisión al legislador, aunque se dice que en tal caso su creación lo será por la vía de la ley orgánica. ( $\mathrm{Fj} 2$ ).

También hay un matiz importante en la STC 35/1983 que diferencia entre poderes públicos y servicio público. La TV es un servicio público en relación con el ejercicio del derecho de rectificación. (Fj. 3).

Por otra parte, la exigencia de Ley Orgánica que la jurisprudencia impone por la ubicación sistemática del art. 20, también relajará sus exigencias acotando el contenido esencial del derecho de información en relación con otros contenidos, como los soportes técnicos. La STC 31/1994 distingue ya entre esa exigencia de ley orgánica para la regulación de los derechos contenidos en el art. 20 y la regulación de lo que son soportes técnicos para el ejercicio de esos derechos ( $\mathrm{Fj}$. 7). Esa distinción entre derechos primarios y derechos instrumentales, en la que los derechos primarios deberían ser desarrollados por ley orgánica, pero no los meramente instrumentales, sirve como criterio de superación de una rigidez normativa, que hubiera sido posiblemente insostenible en una actividad, como la informativa, en la que los avances tecnológicos exigen una revisión legislativa permanente. De ahí que se haya ido a una concepción muy restrictiva del contenido del derecho fundamental, entendiendo que todo lo que excede del aspecto puramente informativo, es atinente a cuestiones técnicas, y puede ser regulado por ley ordinaria, incluso la concesión de canales privados de televisión. ${ }^{6}$ Además, la

6 Cfr. La STC 127/1994, que resuelve el recurso de inconstitucionalidad interpuesto por la Generalitat de Cataluña, Parlamento Vasco y 50 parlamentarios del Partido Popular, contra la ley 
lentitud del derecho frente a la rapidez con que se suceden los cambios tecnológicos, ha favorecido que las resoluciones judiciales fueran relativamente inoperantes. Los recursos frente a los Reales Decretos-Leyes de 1997, de recepción de las Directivas comunitarias, se resuelven en 2005. (STC 329/2005, sobre los descodificadores de TV por satélite).

La consideración de servicio público en fin, ha experimentado una sensible evolución en el desarrollo legal de los preceptos derivados del art. 20, y no solamente en el aspecto formal de la exigencia de la ley orgánica o no, sino también en la acotación del contenido material y los consiguientes límites de la noción de servicio público, que no abarcará cualquier regulación, sino que se compromete con los fines. Un ejemplo de esa concepción se contiene en la STC 206/1990, que razona sobre las limitaciones a ese concepto de servicio público que el Estado puede imponer en materia de comunicación.

La calificación de servicio publico, es constitucionalmente legítima desde el momento en que el legislador la considera necesaria para garantizar —en términos de igualdad y efectividad- determinados derechos fundamentales de la colectividad, pero no es en absoluto una etiqueta que una vez colocada sobre el medio, permita cualquier regulación de la misma, ya que hay en juego derechos subjetivos - los de comunicar libremente el pensamiento y la información- que deben sacrificarse a favor de otros derechos, pero que no puede en modo alguno eliminar. $\mathrm{Y}$ en ese sentido, los cambios en los condicionamientos técnicos, y también en los valores sociales, pueden suponer una revisión de la justificación de los límites. (FJ. n. 6).

En relación con el derecho de huelga de los trabajadores que pertenecen a los medios de comunicación, se han producido algunos pronunciamientos importantes, que tienen mucho que ver con la consideración de servicio público de los medios de comunicación en general y de la RTVE en particular.

Un grupo de sentencias, las SSTC 183 y 184/2006, y la 191/2006, acogen los respectivos recursos de amparo de los Sindicatos convocantes de una huelga general, cuyos servicios mínimos fueron determinados de manera abusiva por las empresas de comunicación. ${ }^{7}$ En el Fj. n. 6 de la STC 183/2006,

10/1988 de la Televisión Privada. Es una ley de concesión de tres canales privados, que no precisa naturaleza de ley orgánica, exigencia que operaría si se regularan aspectos de ese servicio publico que afectaran a los derechos pero en este caso que se regulan solamente las condiciones de acceso de la concesión, (Fj. 4) hay razones que impidan la regulación estatal sin dar cabida a las autonomías. La solución, con todo, estuvo lejos de ser pacífica, porque la sentencia contenía un numero importante de votos particulares que se manifestaron por otra interpretación, de la jurisprudencia sentada en el STC 12/1982 donde se exigía una ley orgánica. O la STC 168/1993, sobre la ley de la ordenación de las telecomunicaciones, que no considera la exigencia de Ley Orgánica, al no ser regulación del derecho sino de las condiciones técnicas del medio. (Fj 4).

7 Los servicios llamados mínimos esenciales, fueron determinados por el RD 531/2002, de 14 de junio, que fue recurrido por las Centrales Sindicales convocantes de la huelga, ante la jurisdicción contencioso-administrativa que desestimó el recurso. La regulación de servicios mínimos permitía a las cadenas de televisión emitir programación grabada, lo que confería al medio una apariencia de normalidad, que diluía la fuerza de la presión de la huelga, hasta desnaturalizar el ejercicio de ese derecho. 
se niega tajantemente por el Tribunal que la regulación de la Ley 4/1980 que califica la radiodifusión y la televisión como servicios públicos esenciales, sirva como criterio de determinación para unos servicios mínimos en el ejercicio del derecho de huelga. Las cadenas de televisión pudieron emitir programación grabada dentro de los servicios mínimos fijados en el tiempo de la huelga. La sentencia anula el RD 351/2002, de 14 de junio, en lo que se refiere a esa posibilidad, porque restringe el derecho de huelga. Y las SSTC 184 y 191/2006 igualmente en relación con otros dos recursos de amparo.

\section{b) LA CONSIDERACIÓN DEL DERECHO A RECIBIR INFORMACIÓN Y SU CONFIGURACIÓN LEGAL}

La evolución experimentada desde el punto de vista constitucional, de protección de los derechos derivados del art. 20, da cuenta, no solamente de la importancia de las libertades de expresión e información, sino que además justifica sobradamente la importancia de tener en cuenta en la fase constituyente, que las libertades de expresión e información eran el presupuesto de la formación de un estado democrático, y la condición del desarrollo de otros valores y principios constitucionales. Sin embargo, la evolución que han experimentado estos derechos de libertad, requiere en los momentos actuales, cuándo el asentamiento democrático parece haberse producido definitivamente, una reflexión acerca de la posible descompensación entre ellos y otros derechos cuyo sacrificio pudo tener justificación en los primeros años de desarrollo democrático. En ese sentido es importante considerar como el discurso jurídico se contrae a la consideración exclusiva de los derechos de libertad de información, pero nada se dice de los derechos de las personas usuarias de los medios de comunicación.

Como contrapunto a esa sobredimensión de los derechos derivados de la libertad de expresión e información, el derecho a recibir información no ha sido objeto de desarrollo por parte de la doctrina y la jurisprudencia, identificándose de manera impropia con el derecho de información. ${ }^{8}$ De ese reduccionismo se desprenden importantes consecuencias en la configuración del modelo final de libertad de expresión en el ordenamiento jurídico, y es la ausencia de un derecho a que las personas puedan exigir a los poderes públicos una información congruente con el modelo de Estado Social, en el que se contienen importantes exigencias de desarrollo de valores vinculados a esa forma de Estado. ${ }^{9}$ No sólo la veracidad o el pluralismo informativo, que pue-

8 Sobre esto llama la atención M. SALVADOR, «El derecho a la información: una asignatura pendiente", en "Constitución y democracia. 25 años de Constitución democrática en España". Vol. I. Universidad del Pais Vasco. Bilbao. 2005, págs. 545 y ss.

9 Para I. VILLAVERDE, la sola garantía de una opinión pública libre por parte del emisor habría sido insuficiente para garantizar el derecho de comunicación. Es el derecho a recibir información, el que contiene una garantía de pluralismo, como un instrumento de participación en el proceso democrático. Op. Cit., pág. 22. 
den estar dentro de las exigencias a los medios de comunicación, sino valores correspondientes a las condiciones de recepción de los mensajes: exigencias en el modelo de prestación del servicio, exclusión de contenidos que contradigan otras agencias de socialización más importantes, como la erradicación de la violencia en relación con los contenidos de paz comprometidos con las instancias educativas, o una regulación de la publicidad respetuosa con los derechos fundamentales de las mujeres.

El derecho a recibir información, no se ha concebido como un derecho directamente derivado de los derechos informativos derivados de los medios de comunicación, sino en relación con otros derechos sociales, como el derecho al consentimiento informado del paciente, o el derecho a recibir información de la situación económica de las empresas, en relación con los derechos sindicales, o en última instancia, como un derecho instrumental de otros derechos, pero en lo que se refiere a un derecho ejercitable ante los medios de comunicación, no hay una posición clara que permita mantener una acción de amparo frente a una información sesgada o parcial. ${ }^{10}$

La doctrina ha puesto de relieve la exigencia de un derecho a recibir información, que tendría la ciudadanía con respecto a los poderes públicos, que vendrían obligados en función el art. $20 \mathrm{CE}$, a facilitar una información veraz $^{11}$. Sin embargo la sobredimensión del derecho a emitir información con respecto del correlativo derecho a recibirla, muestra que no se ha considerado al mismo nivel el derecho de emisión de la información, que el derecho a recibirla. Ciertamente, el derecho de emisión está concernido además por los derechos de libertad de expresión y de imprenta, que arropan un núcleo de derechos de libertad exigibles ante el Estado por parte de organizaciones económicas de extraordinaria magnitud, y en este sentido, las exigencias se estructuran y formalizan ante el Estado de modo muy contundente. La organización y los intereses económicos que nuclean los distintos aspectos de la actividad comunicativa, no pueden en modo alguno compararse a las rei-

10 El TC ha mantenido un criterio también restrictivo a este respecto. En la STC 51/2002, de 12 de marzo, se desestima un recurso de amparo en el que se solicitaba el derecho a recibir información veraz. La solicitud se hace después de haber ejercitado el derecho de rectificación, por una persona a título individual, y el Tribunal considera que no ha lugar al ejercicio individual del derecho a recibir información, y esa persona que carece de legitimación activa para el ejercicio del derecho. El FJ. n. 9 dice que el solicitante no puede arrogarse la representación de una opinión pública defraudada en el derecho a recibir información, "que difícilmente puede atribuirse, dada la inexistencia de los pertinentes cauces de representación. Desde el momento en que el derecho a recibir información se ejerce, fundamentalmente, mediante el simple mecanismo de conectarse o no, en decisión libre donde las haya, al medio en cuestión". Nótese cómo la jurisprudencia ha reducido el derecho a recibir información a una simple elección del medio, sin que quepa hablar de un derecho a los contenidos informativos, que sin embargo, parecen ineludibles para la configuración de la formación de la opinión pública, esencial en un estado democrático.

11 Entendido ese proceso de comunicación como dirigido a «un conjunto de individuos que ocupan una diversidad de posiciones jurídicas cuyo objeto es el acceso a aquella información que les permite colaborar en la vida de su comunidad como consumidores, administrados, votantes, etc, pero sobre todo, como individuos que a través del disfrute de sus derechos fundamentales, ejercen la soberanía colectiva”. I. VILLAVERDE. op. cit., pág. 32. 
vindicaciones que en el mejor de los casos podrían llevar a cabo organizaciones de personas consumidoras y usuarias. Es evidente que no hay una mínima correlación de fuerzas entre una y otra situación. Pero esa patente diferencia, lejos de justificar la actuación de los poderes públicos en referencia a la permisividad que muestran ante los contenidos de los medios de comunicación, debería constituir una razón suficiente para proteger el derecho a recibir la información veraz que debe producirse en un Estado democrático. De ahí la necesidad de cuestionar la naturaleza jurídica del derecho a recibir una información suficiente y veraz por parte de la ciudadanía, como exigencia y presupuesto del derecho de participación política. La doctrina y la jurisprudencia han venido manteniendo en líneas generales que el contenido del art. 20 CE no responde a un derecho de prestación en sentido estricto ${ }^{12}$. Las razones han sido reiteradas. Cualquier injerencia de los poderes públicos en los contenidos de los medios de comunicación, puede llegar a producir una restricción intolerable a la libertad de pensamiento, expresión, creación o difusión de las ideas, y en ese sentido, el Estado ha de ser garante de la libertad de expresión. Pero tal concepción sin duda parte del sofisma de que en efecto, cada profesional de la información elabora sus propios contenidos conforme a los criterios de creatividad que libremente conviene consigo mismo y con fidelidad a la verdad, lo que está bastante lejos de ser la situación actual en la que se desenvuelve la industria mediática. No es necesaria una aguda reflexión, para constatar la manipulación informativa que viven las sociedades democráticas actuales, presas de grandes empresas de comunicación, que instrumentalizan la información en función de sus propios intereses, y de los que subyacen en las políticas financieras de esos medios y de grupos políticos a los que financian y de los que también dependen en mayor o menor grado. ${ }^{13}$ Las consecuencias de esta situación son las de obstrucción informativa, y no las de satisfacción del derecho a la información, con lo que en lugar de instituciones que deben de contribuir al desarrollo del

12 I. VILLAVERDE. Op. Cit., pág. 48. En igual sentido, G. ESCOBAR, "Estatuto de los periodistas". Tecnos. Madrid. 2002, pág. 50, que considera que se trata de un derecho de prestación distinto de otros derechos de esa naturaleza, en cuánto a que su exigibilidad frente al estado es muy relativa, y se refiera solamente a la veracidad. También para J.J. Solozábal el derecho de información constituye un reflejo del derecho de libertad de expresión, que se constituye como un derecho de defensa frente al Estado, límite o garantía de otros derechos. No llega a ser un derecho de prestación. J.J. SOLOZÁBAL, "Aspectos constitucionales de la libertad de expresión y el derecho de información”. En REDC. n. 23. Madrid, págs. 142-144.

13 P. SERRANO, "Desinformación. Como los medios ocultan el mundo". Ed. Península. Barcelona. 2009. El autor llama la atención acerca de las consecuencias de esa ausencia de garantías de veracidad en la información, que contrasta con las exigencias administrativas de calidad en cualquier otra actividad social, que es controlada por los poderes públicos. Los principales problemas que muestran los medios de comunicación en cuánto a su falta de idoneidad serían de una parte las propias condiciones materiales en que se produce la información: empleos precarios de las personas profesionales del medio, control de los grupos de accionistas sobre las editoriales, dependencia de la publicidad, criterios de selección de la información, y concentración de los medios, págs. 19 y ss. 
pluralismo político, los medios se constituyen en instituciones de dirigismo ideológico.

\section{c) EsPeCiAl CONSIDERACión DEL GÉNERO EN EL TRATAMIENTO DE LOS MEDiOS DE COMUNICACIÓN}

Los medios de comunicación deben respetar en función de la formulación constitucional, los derechos derivados de la juventud y de la infancia, y en este sentido, se han venido haciendo intentos, desde los poderes públicos, por establecer límites horarios en la programación, para que determinados contenidos no se emitieran en una franja en que las personas menores pudieran recibir contenidos inidóneos para su formación. Nada dice en cambio la Constitución respecto de la mujer, que no está reconocida como sujeto constitucional débil.

Sin embargo, el despliegue legislativo que ha tenido lugar en relación con los temas de género, ha permitido una importante regulación, en términos cuantitativos, fundamentalmente en lo que se refiere a su tratamiento en los medios de comunicación, y a la regulación de la publicidad. En cuánto a la normativa estatal, la primera ley que regula específicamente la publicidad es la Ley 34/1988, General de Publicidad. Hasta ese momento la regulación legal de la publicidad se contenía en la ley 61/1964, de 11 de junio, por la que se aprobaba el Estatuto de la Publicidad, que se limitaba a regular los aspectos mercantiles de la publicidad. Después de la Constitución Española de 1978 se intenta una regulación desde los principios y valores constitucionales. La novedad fundamental de esta ley en relación con el Estatuto anterior, la constituye el establecimiento de un procedimiento judicial para dirimir las controversias derivadas de la actividad publicitaria. Anteriormente la competencia en materia de publicidad, la tenía un órgano administrativo, el Jurado Central de Publicidad. Pero ahora, tanto la normativa europea, que exige a los estados miembros un proceso garante de la objetividad judicial, como el propio art. 24 de nuestra Constitución que declara el derecho a un proceso judicial mas garante que la actuación administrativa, exigían este proceso, de modo que el título IV se dedica a la regulación de un procedimiento judicial. ${ }^{14}$

La valoración de la ley sin embargo, no responde a su Exposición de Motivos que hacía pensar que se pretendía defender los derechos de los consumidores o grupos sociales. ${ }^{15}$ Podemos encontrar en su articulado algunos de

14 Un análisis de la insuficiencia en la regulación de la publicidad en relación a la imagen de la mujer, en M.L. BALAGUER, "La regulación y el control de la publicidad en el ordenamiento jurídico constitucional español». Boletín de la Facultad de Derecho. UNED. n. 21. Madrid. 2003. Posteriormente, en un análisis de la legislación de género y la publicidad, en "Género y regulación de la publicidad en el ordenamiento jurídico. La imagen de la mujer". Revista Latina de Comunicación Social. N. 63. Enero. 2008.

15 La Ley 34/1988, General de Publicidad, está concebida desde criterios de mercado, para la defensa de la competencia. No es hasta la LO $1 / 2004$, de 28 de diciembre, de medidas de pro- 
estos principios y valores constitucionales, incluso desde el Consejo General del Poder Judicial se intentó informar conforme a ellos, pero como veremos, la fundamental proyección de esta ley sigue siendo mercantil y se intenta regular sobre todo la competencia desleal, la publicidad ilegal y todos aquellos aspectos mercantiles y civiles de la publicidad. ${ }^{16}$

La parquedad con que la Ley General de Publicidad regula los derechos fundamentales afectados por la actividad publicitaria, se hace evidente ya desde el artículo tercero, donde se define la publicidad ilícita. Considera ilícitos cuatro supuestos: La que atente contra la dignidad de la persona o vulnere los valores o derechos reconocidos en la Constitución, especialmente en lo que se refiere a la infancia, la juventud y la mujer. La engañosa, la desleal, la subliminal, y la que infrinja lo dispuesto en la normativa que regule la publicidad de determinados productos, bienes, actividades o servicios.

Esta regulación es meramente enunciativa, y no especifica mínimamente cuándo un anunciante incurre en una lesión a los derechos fundamentales, y a que derechos en concreto. Se limita a decir que se prohíbe la publicidad lesiva de derechos fundamentales, que en realidad no tendría ni que decirlo, porque de hecho son derechos protegidos por la Constitución.

También la publicidad subliminal se define de manera imprecisa. Se considera subliminal la publicidad que mediante técnicas de producción de estímulos, de intensidades fronterizas con los umbrales de los sentidos, pueda actuar sobre el público destinatario sin ser conscientemente percibida. Sería necesario redefinir este concepto para calificar de algún modo la inmensa mayoría de la publicidad que se basa precisamente en la adherencia al producto de valores que nada tienen que ver con él.

Posteriormente, la Ley Orgánica 1/2004, de 28 de diciembre, de medidas de protección integral contra la violencia de género, regula la publicidad en la Disposición Adicional sexta, que modifica la Ley 34/1988, de 11 de noviembre, General de Publicidad. Consciente esta ley integral de la importancia que para la violencia de género tiene la publicidad en la que el cuerpo de la mujer se utiliza como reclamo publicitario, modifica la regulación en un intento

tección integral contra la violencia de género, cuándo se concibe una regulación de defensa de la imagen pública de la mujer en la publicidad, en la consideración de que en la violencia de género tiene una importancia trascendental la creación de los estereotipos del cuerpo de la mujer. Sin embargo su regulación es bastante insatisfactoria. Sobre la regulación legal de la publicidad y el género, M.L. BALAGUER, «Mujer y Constitución». Cit., págs. 198-217.

16 El desinterés de la industria publicista en la defensa de estos valores es comprensible desde esta consideración comercial. En la medida en que el mensaje apura más los límites, es tanto más eficaz. Pese a los autocontroles publicitarios, es de suponer que la aspiración del anunciante está en conseguir la máxima utilidad en el mensaje. Por otra parte, no hay ningún organismo real de control en la industria publicitaria. El Observatorio de Publicidad que se crea en marzo de 2000 por la Asociación Española de Anunciantes, tiene como objetivo el estudio y seguimiento de la actividad comercial pero no se plantea el contenido de los valores transmitidos por la publicidad. En expresión del propio observatorio, «el objetivo de esta organización es constatar y reflejar permanentemente la realidad de los medios de comunicación, en su vertiente publicitaria, manteniendo como máxima la credibilidad, y realizando mediciones rigurosas e incuestionables". 
de controlar cierta actividad publicitaria que presenta a la mujer en situaciones que puedan incitar a la violencia. Sin embargo, esta nueva regulación no ha resultado efectiva para el control de la actividad publicitaria.

Finalmente, en el ámbito estatal, la LO 3/2007, de 22 de marzo, para la igualdad entre mujeres y hombres, regula las exigencias de los medios de comunicación en relación con el género. Respecto de la RTVE, de la Agencia Efe, de los medios de titularidad privada, y de la autoridad audiovisual, el art. 36, dice que «los medios de comunicación social de titularidad pública velarán por la transmisión de una imagen igualitaria, plural y no estereotipada de mujeres y hombres en la sociedad, y promoverán el conocimiento y la difusión del principio de igualdad entre mujeres y hombres". El art. 37, entre los objetivos de programación de la Corporación RTVE, «reflejar adecuadamente la presencia de las mujeres en los diversos ámbitos de la vida social, utilizar el lenguaje de forma no sexista, adoptar mediante la autorregulación, códigos de conducta tendentes a transmitir el contenido del principio de igualdad, colaborar con las campañas institucionales dirigidas a fomentar la igualdad entre mujeres y hombres y a erradicar la violencia de género". En relación con los medios de titularidad privada, el art. 39 pf. 1 dice que todos los medios de comunicación respetarán la igualdad entre mujeres y hombres, evitando cualquier forma de discriminación. Y el 2 que las Administraciones públicas promoverán la adopción por parte de los medios de comunicación de acuerdos de autorregulación que contribuyan al cumplimiento de la legislación en materia de igualdad entre mujeres y hombres, incluyendo las actividades de venta y publicidad que en aquellos se desarrollen. El art. 40 también contiene una exigencia para los Consejos Audiovisuales, al decir que «las Autoridades a las que corresponda velar porque los medios audiovisuales cumplan sus obligaciones adoptarán las medidas que procedan, de acuerdo con su regulación, para asegurar un tratamiento de las mujeres conforme con los principios y valores constitucionales".

Finalmente, sobre la publicidad el art. 41 dice que «la publicidad que comporte una conducta discriminatoria de acuerdo con esta Ley se considerará publicidad ilícita, de conformidad con lo previsto en la legislación general de la publicidad y de publicidad y comunicación institucional.

Tampoco esta regulación satisface la necesidad de afrontar el problema de la mujer en relación con la actividad publicitaria. Los mecanismos para inhibir o prohibir aquellos anuncios que muestran el cuerpo de la mujer como objeto de deseo del hombre, o supeditación o consideración objetal de la mujer, no permiten una solución fácil y rápida. Los procedimientos arbitrados en la ley exigen procesos judiciales lentísimos en relación a la rapidez con la que en los medios de comunicación se desenvuelven los spots publicitarios, de manera que la solución jurídica frustra sus resultados al conseguir una sentencia definitiva muchos años después de que la publicidad haya sido emitida. Por otra parte, las agencias de publicidad, pueden buscar un efecto aún mas llamativo en anuncios susceptibles de polémica, porque su rentabilidad pública puede ser mayor en los casos en que esa publicidad sea discutible, al conseguir concentrar una mayor atención social. 


\section{MECANISMOS DE CONTROL DE LOS CONTENIDOS}

\section{A) La Autorregulación}

La objeción de los medios de comunicación a la regulación de lo que ellos mismos denominan "libertad de expresión", deriva fundamentalmente de la imposibilidad de poner límites a la creatividad, que se considera en las sociedades actuales un indiscriminado factor de progreso y avance cultural, sin límites, porque éstos pueden coartar el proceso creativo, lo que redundaría en un perjuicio colectivo irreparable. En tal sentido, se estima adecuada la autorregulación por el sector, que podría imponerse a sí mismo los límites que considerase suficientes y adecuados.

Los sistemas de autorregulación son variados. Tienen en común la dependencia de la iniciativa libre del medio o los medios, y la voluntad propia de fijar el contenido y los límites, pero pueden consistir en normas deontológicas, Estatutos de redacción, Defensores del Lector, Ombusman o Consejos. ${ }^{17}$

La autorregulación, pese a la consideración positiva que parece ofrecer, adolece de legitimación social desde su propia concepción. No hay precedentes de que sector alguno de la producción en un Estado se autorregule. No es pensable que la producción textil, agrícola o de la construcción, creara sus propias normas de funcionamiento en relación con los productos que fabrica, sin sujeción a normas que disciplinen su actividad. Pero además, es que no es pensable tampoco que puedan regularse en un convenio privado, cuestiones tan trascendentales como la defensa de todos aquellos derechos fundamentales que afectan a la ciudadanía, en relación con los contenidos transmitidos por los medios de comunicación. La determinación de los factores económicos sobre las condiciones de regulación, es no solamente presumible, sino razonable. ${ }^{18}$ Por otra parte, no hay base teórica alguna en la que sustentar la idea de que los medios de comunicación son los garantes de la libertad de expresión y del pluralismo político. No lo serían siquiera los de titularidad pública, que deberían estar sujetos a mayores límites constitucionales, pero menos aún las empresas privadas, cuya legítima finalidad económica entra en flagrante contradicción con las exigencias del respeto debido a los contenidos alineados con la Constitución. La competencia y la libre concurrencia del mercado, no son garantía, sino que exigen la garantía que el Estado está obligado a prestar en relación con las exigencias de respeto a la dignidad de la persona establecidas en el art. $10 \mathrm{CE}$.

17 Una sistemática de estos instrumentos y de las funciones que están llamados a cumplir, en V. NAVARRO MARCHANTE, La (auto) regulación de la práctica informativa: una aproximación a la situación española actual”. En RDEC. N. 84. septiembre-diciembre. 2008, págs. 182 y ss.

$18 \mathrm{La}$ autorregulación de las condiciones de los contenidos televisivos, se intentó en diciembre de 2004, con la firma de la televisión pública estatal y las cadenas privadas de implantación estatal. No solamente era por completo insatisfactoria con las mínimas exigencias constitucionales de respeto a los derechos fundamentales, sino que además ha sido sistemáticamente incumplida. 
La exigencia por tanto de una regulación que atienda a los derechos derivados de la libertad de información, es exigencia y condición del desarrollo democrático, y del pluralismo político contenido en los valores de la Constitución, (art. 1.1).

La desregulación, que se presume garante de la libre creatividad, es sin embargo un factor de obstaculización de la democracia y del pluralismo. ${ }^{19}$

Los medios de comunicación, en general, han preferido apelar a la autorregulación, y ésta parece funcionar razonablemente bien en países como Gran Bretaña. En este sentido, el pasado 9 de diciembre de 2004 se firmo un acuerdo para la autorregulación de los contenidos televisivos con relación a la infancia entre el gobierno español, la televisión pública y tres operadores, Sogecable, Telecinco y Antena3. Sin embargo, no se han mostrado efectivos en la práctica,

Por tanto, parece necesario crear Consejos Audiovisuales con poder sancionador que velen por la información veraz y respetuosa con los derechos humanos. ${ }^{20}$

\section{B) Los COnsejos Audiovisuales}

a) La necesidad de un Consejo Audiovisual estatal

La concepción de los medios de comunicación desde la desregulación como garantía de libertad, y el fracaso de la autorregulación, han tenido como consecuencia la generación de una forma de control a través de autoridades expertas e independientes, nombradas por los Parlamentos, o por éstos y los Consejos de Gobierno, que vigile y controle la actividad y contenidos de programación.

Bajo la denominación de Consejos Audiovisuales se regulan muy diferentes contenidos en las diferentes CC.AA. en algunas, se crea directamente un Consejo con específicas funciones de control de contenidos, (Andalucía o Cataluña) y en otras se regula genéricamente el sector audiovisual, (Galicia o Navarra).

Estas autoridades independientes son de muy reciente aparición en Europa. ${ }^{21}$ Su naturaleza jurídica es pública, tienen personalidad jurídica propia, pero son autónomos en cuánto a su presupuesto, tienen una ley de creación, a veces un reconocimiento estatutario, y un reglamento de funcionamiento. Se les ha llamado Administración instrumental, por cuánto sirven a intereses

19 Sobre la relación entre regulación y democracia, B. DÍAZ NOSTY, "El Consejo Audiovisual como institución de cultura democrática", en Foro RTVA. Sevilla. 1999.

20 En general, sobre los Consejos Audiovisuales, J. BOTELLA CORRAL, "La regulación independiente del sector audiovisual español: una reflexión sobre problemas, perspectivas y posibilidades". En Revista catalana de Dret Public, n. 34. Barcelona. 2007. Este número, monográfico, contiene además un importante estudio doctrinal acerca de los diferentes Consejos Audiovisuales en las Comunidades Autónomas. 
públicos concretos, o descentralizada en la medida en que no se articulan con la Administración central, sino que funcionan de manera autónoma. Su aparición en la formulación actual de "autoridades independientes" está ligada precisamente a la creación en 1980 del llamado "ente público" de la RTVE. Junto a otras instancias económicas, se consideró que algunas instituciones públicas, por su particular consideración, no debían estar sometidas a la Administración General del Estado, y debían garantizar la neutralidad en su gestión.

En el ordenamiento estatal está prevista la creación de un Consejo Audiovisual. Desde 1997 hay iniciativas legislativas en este sentido, proposiciones de ley de algunos grupos parlamentarios en el Congreso, y una consideración doctrinal muy generalizada de la necesidad de que se regule esta institución a nivel estatal, para facilitar una relación adecuada con las CC.AA. La ley $17 / 2006$, de 5 de junio de la radio y la televisión de titularidad estatal, centra en su exposición de motivos, el origen del art. 20 CE como presupuesto de un servicio público comprometido con la intervención parlamentaria, y con la "supervisión de su actividad por una autoridad audiovisual independiente".

El Consejo Audiovisual es uno de los tres controles externos de la RTVE, los otros dos son el Parlamento y el Tribunal de Cuentas. Estando prevista la creación del Consejo Asesor y los Consejos informativos, en un plazo de seis meses a partir Disposición Adicional Tercera, no lo está la del Consejo Audiovisual, que hasta fechas muy recientes no ha sido regulado.

El hecho de que en España no haya habido hasta el momento una regulación estatal de los Consejos Audiovisuales, que dote de una legislación básica en la materia, ha tenido como consecuencia la irregular situación de las CC.AA. en torno al objeto, contenido y funciones de los Consejos Audiovisuales en las CC.AA. ${ }^{22}$

El art. $4^{\circ}$ de la Ley 17/2006, de 5 de junio, de la radio y la televisión de titularidad estatal, prevé la creación de una autoridad audiovisual, a la que corresponde "la supervisión del cumplimiento de la misión de servicio público de radio y televisión, por parte de la Corporación RTVE, para lo que podrá adoptar las recomendaciones o resoluciones que prevea su regulación."

Asimismo, "podrá requerir a la Corporación RTVE y a sus sociedades los datos e informes necesarios para el ejercicio de sus funciones. La información así obtenida, será confidencial y no podrá ser utilizada para fines distintos a los propios de sus competencias".

21 Acerca de las autoridades independientes, y su análisis comparado en los principales Estados de Europa, M. SALVADOR, "Autoridades independientes". Edit. Ariel. Barcelona. 2002.

22 Los intentos del Estado en este sentido han sido más bien tímidos. Una moción del Senado de 1995, que instaba al Gobierno a crear una Comisión del Audiovisual. También se ha ignorado la Recomendación (2000) 23 del Consejo de Europa, adoptada por el Comité de Ministros, de 20 de diciembre, que insta a los Gobiernos de los Estados miembros a instaurar autoridades independientes de regulación del sector de la radiodifusión.Finalmente, se ha aprobado en fechas recientes un proyecto de Ley del Consejo Audiovisula estatal por el Congreso de los Diputados, pendiente aún del trámite de aprobación por el Senado. 
España es uno de los pocos países europeos que no dispone de un Consejo Audiovisual Estatal, a pesar de que en 1995 se aprobó en el Senado por 235 votos a favor y 3 en contra, una moción que instaba al Gobierno a crear una Comisión del Audiovisual o Defensor de carácter independiente. Actualmente, el informe para la Reforma de los Medios de Comunicación de Titularidad Pública elaborado por los "Sabios" reconoce la necesidad de su creación y su función básica: velar por la garantía y protección de los derechos fundamentales. ${ }^{23}$

Las características comunes a todas las instituciones de control externo, con alguna excepción, ${ }^{24}$ es la de ser autoridades independientes, que participan de la naturaleza de estos órganos: presupuesto propio, normativa propia por ley y autonomía total en su funcionamiento.

\section{b) Los Consejos Audiovisuales en las CC.AA.}

El primer Consejo Audiovisual que se crea, es el de Cataluña. ${ }^{25}$ Posteriormente, el Consejo Audiovisual de Galicia, ${ }^{26}$ el Consejo Audiovisual de Andalucía ${ }^{27}$, el de Navarra, ${ }^{28}$ y el de la Comunidad Autónoma de Madrid. ${ }^{29}$

\section{CONCLUSIONES}

La libertad de expresión y la libertad de información son presupuestos de una sociedad libre y democrática, y se han configurado en nuestro ordena-

23 Plataforma Europea de Autoridades Normativas. (EPRA). Se crea en 1995 para agrupar a las diferentes instituciones que lleven a cabo funciones de control de los medios de comunicación. Consta de un Comité Ejecutivo formado por un presidente y hasta cuatro vicepresidentes y un secretariado. Sus funciones son las de facilitar información entre los miembros, para unificar criterios sobre los objetivos que cumplen las Autoridades Normativas en cada estado.

24 El ya derogado Consejo Audiovisual de Madrid, no tenía esa consideración de autoridad independiente, según M. Salvador y J.A. Camisón Yagüe «El Consejo Audiovisual de la Comunidad de Madrid y la Comisión Técnica Audiovisual", en "El derecho de la Televisión. Situación y perspectivas en la Comunidad de Madrid”. Dykinson, s.1. Madrid. 2004. Pg. 145.

25 La ley 8/1996, de 5 de julio, de regulación de la programación audiovisual distribuida por cable. La Ley 3/2004, de 28 de junio modifica la ley de creación. Ha tenido importantes modificaciones. La Ley 2/2000, de 4 de mayo, del Consejo Audiovisual de Cataluña, modificada por la Ley 31/2002, luego por la Ley 3/2004, de 28 de junio, y finalmente, por la Ley 22/2005, de 29 de diciembre, que regula la comunicación audiovisual de Cataluña, todas del Parlamento de Cataluña.

26 La Ley 6/1999, de 1 de septiembre, del Audiovisual de Galicia.

27 Ley 1/2004, de 7 de diciembre. Con anterioridad se había creado por Decreto 52/2000, de 7 de febrero, del Gobierno de Andalucía, el Consejo Superior Andaluz del Audiovisual.

28 Ley 18/2001, de 5 de julio, por la que se regula la actividad audiovisual, modificada por la Ley foral 17/2002, de 6 de junio, y la Ley Foral 3/2005, de 7 de marzo.

29 Ley 2/2001, de 18 de abril, de la Comunidad autónoma de Madrid, que regula los contenidos audiovisuales y servicios adicionales. Por la ley $2 / 2006$, de 21 de junio, se ha suprimido esta institución. 
miento constitucional vinculados inexcusablemente al concepto de Estado Social y Democrático de Derecho.

Por derivación histórica, los derechos de libertad de expresión e información han adquirido en nuestro ordenamiento una sobredimensión respecto de los derechos individuales, en un intento de compensación de un régimen anterior ausente de libertades, donde las limitaciones a estos derechos se identifican con posiciones cercanas a ese régimen. Esto convierte a estos derechos como preferentes sobre otros, en la vía de la justificación de los valores del pluralismo informativo y la contribución a los valores superiores del ordenamiento.

La mas clara manifestación de ese derecho preferente es la desregulación de la materia informativa, en la convicción de que cualquier regulación es limitativa de esos derechos, no estaría por esta misma razón, justificada. No hay sin embargo justificación en un Estado de Derecho para mantener la desregulación en espacios ni materias, bajo la mera consideración de que toda regulación es limitativa. Por dos razones, la primera porque no toda regulación es siempre limitativa en sí misma, y la segunda porque la sola vinculación de los derechos de información a los valores superiores del ordenamiento, no le permite mantenerse al margen de la legalidad. La protección del derecho no es la protección del exceso del derecho, y la intermediación legal puede ser delimitadora de esos derechos como de los demás derechos fundamentales que han sido objeto de regulación legal. Esta consideración omnímoda de los medios, descompensa de forma importante el mismo contenido de los derechos, que comprende tanto el derecho a la emisión, (informar), como el de recepción, (ser informados).

Las opciones de autorregulación, como las de control de los medios que han adoptado algunas CC.AA. son reveladoras de la necesidad de control de los medios de comunicación. Este control debe ser independiente del control de los gobiernos, autónomo, y sobre todo efectivo. Las CC.AA. que han regulado esta institución, en sus EE.AA. y en leyes de creación, han pretendido evitar la concentración de medios, el respeto a los derechos fundamentales, y el control en las adjudicaciones administrativas, con potestades sancionadoras en su caso. Sin embargo, la capacidad jurídica de que se las dota es relativamente escasa para pretender su eficacia. Su configuración, su composición, al margen de las asociaciones de consumidores y usuarios, con tan limitadas capacidades ejecutivas, no les permite la retirada de un anuncio publicitario por ofensivo que pueda ser a grupos o género, ni evitar la concentración excesiva de los medios. Surgen así con una limitación definitiva, porque no podrán cumplir su finalidad ni en materia de derechos fundamentales ni en materia de concentración de medios. 
TITLE: The regulation of the Audiovisual Councils in the Spanish legal system.

ABSTRACT: The regulation of Audiovisual Councils in Spanish Law creates relevant problems concerning fundamental rights established by the Spanish Constitution. Freedom of expression may be affected. Therefore, the Constitutional Court has ruled on applicable limits to Freedom of Expression, on the ground on due respect to other right and interests constitutionally protected. Rules on content control of mass media must respect these constitutional limitations.

Resumen: La regulación de los Consejos Audiovisuales en nuestro ordenamiento jurídico presenta importante problemas en relación con derechos fundamentales constitucionalmente reconocidos. El derecho a la libertad de expresión, puede sufrir importantes recortes en este sentido. De ahi que la jurisprudencia del Tribunal Constitucional haya debido determinar los límites de este derecho en relación con otros bienes y derechos también constitucionalmente garantizados. Los mecanismos de control de los contenidos de los medios de comunicación deben atenerse a esos limites constitucionales.

Key Words: Audovisual Councils. Mass Media. Content Control.

Palabras clave: Consejos Audiovisuales. Medios de Comunicación. Control de contenidos. 